Historic, Archive Document

Do not assume content reflects current scientific knowledge, policies, or practices. 


\section{THERE IS}

\section{MONEY IN NUTS}

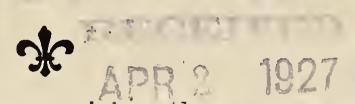

Nut culture is more promising than any species of fruit at the present time. A few thousand acres already planted has served to show that this is a natural climate for English Walnuts and filbers, two of the more important items in the United States imporations of nuts amounting to one million dollars weekly. Production of nuts requires a minimum amount of attention and labor and the returns are highly satisfactory.

In 1923 the United States imported 28,000,000 pounds of filberts. During 1925 we imported only a little over $19,000,000$ pounds of filberts due to higher prices in comparison to other nuts. The 1925 imports of walnuts amounted to more than $75,500,000$ pounds. These imports w. ... win... tion to the domestic production of these nuts which in the case of walnuts amounts to over $50,000,000$ pounds annually.

An important phase of the American nut situation is the very superior quality of the nuts resulting from first class cultivation, fertilization, irrigation, etc. In the Pacific Northwest are grown the finest walnuts the world produces. This is due to variety partially but largely to the more moderate temperatures prevailing during the maturing of the nut resulting in a clear white pelicle and a much better price. In southern California the yicld of Franquette walnuts seldom n...man $50 n$ lbs. per acre while in western Oregon and Washington this variety frequently exceeds $2000 \mathrm{lbs}$. per acre due to climatic conditions favoring heavy bearing of this variety.

Filberts are not a cultivated crop in Europe, tho planted extensively for home consumption and for export. These plantings for the most part are on rocky hillsides too steep for anything else. No attempt has been made to secure improvement in varieties or culture during the past 75 years and the improvements made prior to that were insignificant. The nuts are sold to buyers at prices ranging from four to twelve cents per pound and the grower believes he is getting a very good price never dreaming that a superior article would sell on our markets over here at prices ranging upward of $30 \mathrm{c}$ per pound. The American is not slow to find a way in which to grow a thing better and the case of filberts is no exception. Under conditions of good culture and fertile ground it is not unreasonable to expert average yields up to and including 3000 pounds per acre, with occasional crops averaging up to 5000 pounds per acre. Present prices on filberts vary widely, some growers getting as much as $30 \mathrm{c}$ per pound while others get considerably less than this 
price. It is expected that average prices on the homegrown product will not stray far from $25 \mathrm{c}$ per pound during the next ten years and that this may be the basic price for a much longer period. The formation of marketing organizations will in a comparatively short time control the price of these nuts as does the California Walnut Growers Association control the price of walnuts to a very great extent.

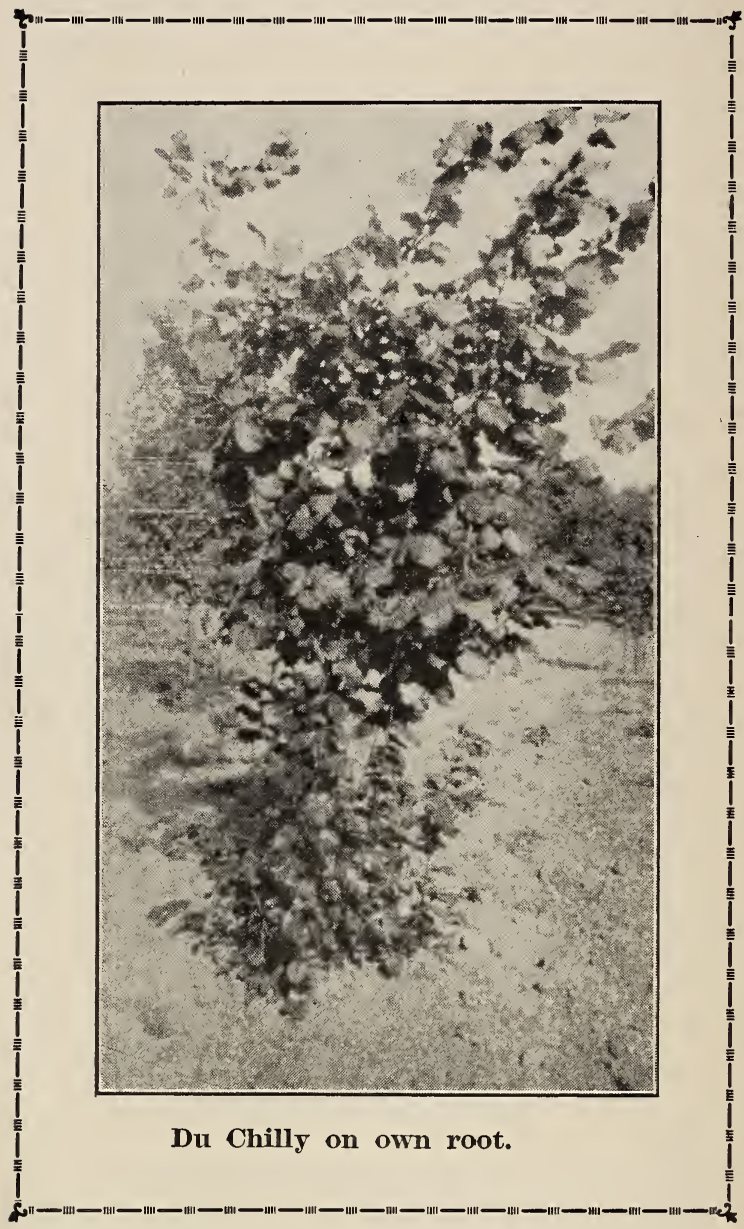

The suggestion is made to the prospective planter of nut trees that he depend upon his nurseryman to advise him in regard to planting distances, varieties, pollination, depth of planting, soils and kindred subjects connected with the establishment of an orchard that is expected to provide the income for future years. The few general suggestions given here are but a few of the highlights and should these fail to cover the situation or your particular case you are expected to state your problem in detail and ask advice in regard to same.

English walnuts are hardy trees under some conditions and very subject to winterkill under 
other conditions. Briefly, the walnut tree must go dormant early in the season and it is a tree that will not go dormant if conditions permit of late season growth.

Late irrigation or late cultivation serve to prolong the growing season and will prove disastrous in case of severe early winter weather. While in many cases where care has been taken to cease cultivation in good season the walnut has withstood the frost that killed the apple; the wisdom of experience would tend to show that only the frost free upland should be considered in locating the walnut orchard with very few exceptions. Where good air drainage is available the walnut will stand 50 degrees below zero better than most fruit trees.

The Vrooman Franquette is the only variety of walnut being propagated to any extent in the Northwest. The trees begin bearing in one to four years and keep it up with regularity bearing large crops of the very finest walnuts as they grow older. Many people confuse this variety with the seedlings emanating from it and enjoying a widespread circulation throughout this district. The seedling trees produce very fine nuts but are very apt to take from eight to fifteen years before they start in bearing. All the better trees are grafted on roots of the California black walnut.

Walnut trees are spaced from forty to sixty feet apart and intercrops are grown during the early life of the planting. The trees are kept well cultivated and fertilized to get best results. At seven years of age the well cared for trees should produce in the neighborhood of twenty pounds per tree. At fifteen years the yield should be near one hundred pounds per tree. One can depend upon full bearing as long as the trees are not too crowded which is a condiiton easily remedied by cutting out some of the trees. The cost of harvesting walnuts is about one cent per pound. The marketing cost is so slight that after allowing for grading and marketing costs the field run product should bring slightly better than twenty five cents per pound at present basic prices.

Filbert trees are spaced from ten to thirty feet apart as they bear early in life and grow very slowly in comparison to the walnut tree. There are many varieties being propagated here but of these only two are of sufficient importance to describe here. The most popular is the Barcelona, a fast growing tree, bears very well, the nuts are large and nearly round. It is pollinated by the White Aveline, the Red Aveline, the Daviana, and to some extent by the $\mathrm{Du}$ Chilly.

The $\mathrm{Du}$ Chilly is gaining ravor very rapidly as a commercial variety. The nuts are oblong, of 
large size and excellent quality, often bringing 25 per cent more than the nuts of the Barcelona. The tree is extremely hardy and bears prolificly The pollinator for this variety is the Gasaway, Alpha, or Clackamas.

The bearing of a filbert orchard hinges upon correct pollination as all filbert varieties are selfsterile and dependent upon cross pollination between varieties. Thus we plant ten or more trees to each acre to act as pollinators. If we plant extra large pollinators we may get along with a less number for an eight year old pollinator will produce more pollen than an acre of four year olds and so on. Since wind is the pollinating agent it is important that the pollinators be on the windward side of the orchard during the pollinating season which is usually from January to April, depending upon variety. As pollinators are often not available in sufficient quantity the tendency is to leave them out or to substitute very small pollinators where it is of considerable importance that the pollinators be of the largest size. Large pollinators may mean several hundred dollars in increased returns during the early years of the planting which is the time when bearing is the most needed, as a usual thing. Often people see a scattering of nuts over their orchard and think that their pollination is $\mathrm{O} . \mathrm{K}$. when as a matter of fact the trees are producing only a tenth of what they should

The grade of nursery stock planted has a great deal to do with the commercial bearing age of the orchard also the better the grade of nursery stock the greater the freedom from loss of trees through blight. Until lately the filbert layer was deemed the ideal tree to plant but it is conceded now that there is less danger of blight and that the orchard will be several years earlier in commercial bearing if an older grade of nursery stock be planted. Thus counting the filbert layer as a one year old tree we have trees one year in the nursery termed two year olds, etc. Since the filbert trees are for the most part grown from layers or cuttings there is a great deal of difference between these trees and the other stock that comes from the nurseries. The predominance of small sizes results in great confusion in the mind of the prospective purchaser who, if not previously informed, would expect to get trees comparable in size to the apple and pear trees he had been buying previously. One of the best rules is to buy the trees by the age of the root system figuring that with a good sysem of roots the trees will take right hold and grow. There is however in any age of tree a great difference in height and other desirable features. The real way to buy trees is to go to the nursery and after having been shown the various grades pick the one most satisfactory to yourself. 
Another cultural problem often ignored entirely is filbert blight. This disease attacks the filbert trees but one or two years planted and is largely the result of an inadequate supply of food and moisture. The blight bacteria are present in some soils and not in others but in the worst infected districts once the tree is established it is immune to further attack. The disease is first noticed as a dark band encircling the trunk about

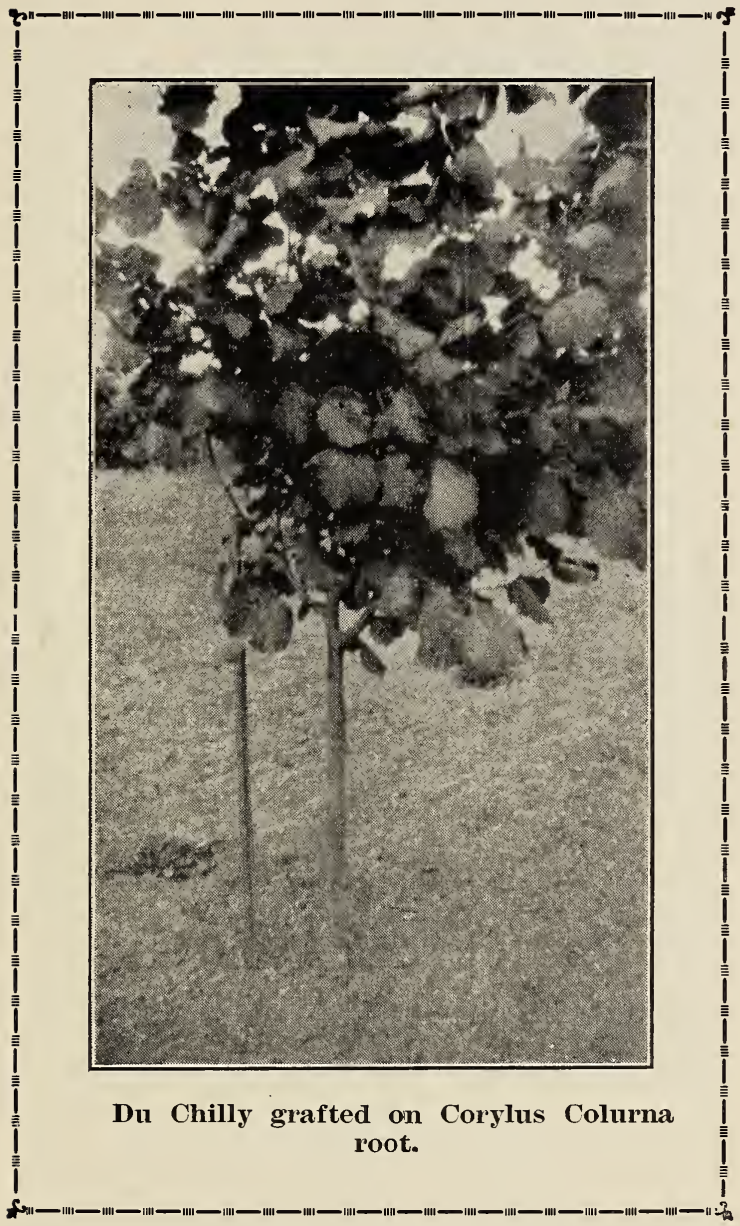

an inch or two above the ground. This prevents the food manufactured in the leaves getting to the roots and while the tree may make a good growth the following season it soon becomes apparent that the tree is dead.

To get the greatest freedom from this disease plant only the better grades of trees for the sturdier root systems and the thicker bark prevent infection. Should you have trees that died from this cause replant with a perfect specimen taking care to see that it gets started off right and you will have no trouble.

Quite often the attempt is made to limit the commercial filbert area to the district bounded by 
the Cascade mountains and the Pacific ocean but under irrigation in eastern Oregon and Washington the filbert evidently thrives with every indication of giving better results there than on the coast for while it is admirably adopted to the rainy climate experienced there it is also malning a name for itself in Hood River and the Yakima valley. Evidently in a few years there will be thousands of acres of filberts in the eastern portions of these two states.

Filbert orchards are being planted in nearly every state in the Union as well as in several Canadian provinces. Successful filbert orchards have long been located in British Columbia and Ontario, Canada, and it is in these two provinces that considerable acreage will be planted during the next few years. That there will be much enthusiasm for filbert culture in the eastern part of the United States is extremely doubtfu, at least for some time to come.

Production figures on an orchard of 20-year-old filbert trees in Lane county, Oregon, have been offered by George Dorris of Springfield, owner of the orchard, who writes as follows:

"In our first planting of 100 trees made 20 years ago were 25 Barcelonas. These trees were planted in a solid block. Several of the original trees were lost and were later replaced with younger trees. From this block of trees as it stands we have just harvested at the rate of 5040 pounds per acre. These weights were obtained on the basis we paid the pickers for gathering the crop and no deductions were made for blanks and shrinkage. As this block is perfectly pollinated by Davianas of the same age, the blanks rarely run over 1 per cent, and the gleanings of the trees will result in more than balancing any shrinkage there may be. No record of the production of these trees was made during the last two years, but three, four, and five years ago, the yield ran from over $3400 \mathrm{lbs}$. to over $3600 \mathrm{lbs}$. per acre. Only one tree in this block, owing to too close planting, was so situated that we could get its individual yield, which was 69 pounds. As much as eight years ago some individual trees in this block produced over 50 pounds per tree.

"Our twenty-three year old trees have not yet been harvested, but as they are under better conditions we feel confident that they will do as welr, if not better. One tree on which the squirrels were working was picked and yielded over 70 pounds. Another tree was picked for the purpose of making an exhibit at the county fair, where its yield of 96 pounds may be seen. During the week anyone interested may see from 70 pounds to possibly 100 pounds lying on the ground under 23 year old trees. At that rate the yield of 70 trees to the acre will be considerably in excess of the 5000 pounds we estimated. Under a 14-year-old tree as high as 60 pounds may be seen. We gathered 30 pounds and more from a number of 11-year-old trees, and have the second gatherings yet to make. 
'When anyone tells you that 2000 pounds per acres wil not be frequently gathered in the Willamette valley from strictly first class ten or twelve year trees and that the yield will not increase up to 4000 pounds at 20 to 25 years of age, when all conditions are favorable, you can put it downs that he does not know what he is talking about. When anyone quotes this statement, however, please do not omit 'strictly firstclass trees under favorable conditions.' That means a full stand of large, sturdy trees, on suitable soil, with the all important factor of perfect pollination, and a good crop year."

Mr. L. F. Russell, Washougal, Washingtor; owns an orchard of filberts twenty years old from which he harvested this year an average of 50 pounds from each Barcelona tree. Individual trees went as high as 75 pounds but owing to severe loss of top from sleet and the competition furnished some of the trees by a fir grove, the average was not as great as it might have been. Davianas and Red Avelines are mostly responsible for the pollination in this grove.

W. A. Ward, Battle Ground, Washington, harvested 4 1-9 pounds of Du Chilly nuts from each of 400 four year old trees. 12 year old trees in the adjoining orchard bore an average crop in excess of 25 pounds per tree with the trees fifteen by twenty feet apart. These were Du Chilly trees with Alpha and Gasaway pollination.

Gorge Gasaway, Battle Ground, Washington, harvested 38 pounds from each of two eight year old trees. Several four year trees averaged 10 pounds per tree. These were $\mathrm{Du}$ Chilly trees pollinated by the Gasaway variety. The trees were well cared for and fertilized.

During the past five or six years Richard Turk has been greatly interested in learning more in regard to the Asiatic tree hazels and has thus far discovered at least six species and has succeeded in getting into this country four species. The advantage of grafting filberts on tree hazels is manifold. Better growth and greater bearing are the most noticeable results. Second to this and also of considerable importance is the complete elimination of the sprouts about the base of the filbert tree. A very remarkable opportunity is offered to share in the production of nursey stock to be grown from 3000 pounds of these nuts. $\$ 1500$ is required for a half interest in this project.

The Turks, father and son, own and have charge of over seventy acres of nut trees most of which is just coming into bearing and consisting of walnuts and filberts from one to seven years old and a walnut orchard of 24 acres planted in 1910 and grafted over by Richard Turk's crew of walnut grafters in 1923 to the true Vrooman Franquette. The original trees in this grove were seedling Franquettes. The production of this acreage is expected to amount to several thousand dollars this season. 


\section{PRICE LIST}

\section{PRICE CHANGE ON GRAFTED WALNUTS}

4 to 6 foot one year grafts, $\$ 1.15$ each. 6 to 8 foot one year grafts, 1.40 each. 8 to 10 foot two year grafts, 1.70 each. 10 to 12 foot two year grafts, 2.00 each. Other sizes all sold. Limited quantities only in above sizes.

\section{Filberts}

The thousands of trees sold prior to the issuing of this price list leave me short on all grades and completely sold out on some. What I have left is quoted here.

Barcelona

Three and four years. Straight one and two year tops mostly.

3 to 4 feet, $50 \mathrm{c} 4$ to 6 feet, $60 \mathrm{c} \quad 6$ to 8 feet, $75 \mathrm{c}$ Daviana

White Aveline. Barcelona pollinators. Barcelona prices.

$\times$ Red Aveline

Du Chilly

Two and Three Years.

2 to 3 feet, $40 \mathrm{c} 3$ to 4 feet, $50 \mathrm{c} 4$ to 6 feet, $60 \mathrm{c}$ Alpha

Three years. Du Chilly pollinator.

2 to 3 feet, $75 \mathrm{c}$.

Gasaway

Two year grafts on five year seedling roots. Du Chilly pollinator.

3 to 4 feet, $\$ 1.50 \quad 4$ to 6 feet, $\$ 1.75$ 6 to 8 feet, $\$ 2.00$

Corylus Colurna

Two year Turkish tree hazel seedlings.

1 to 2 feet, $75 \mathrm{c}$.

Corylus Jacquemontii

One year tree hazels from India.

Up to 18 inches, $50 \mathrm{c}$. Nuts $\$ 1.00$ per pound.

Corylus Chinensis

Chinese tree hazel seed from interior of China. Nuts $\$ 2.00$ per pound.

Terms are cash with order unless special arrangements are made otherwise. Large orders are delivered free of charge to points within 100 miles. All prices are f.o.b. Vancouver. To secure the benefit of the lowest possible prices contract in advance for your needs.

Yours very truly,

RICHARD H. TURK,

"The NUT Man"

Route 5, Vancouver, Washington

Located on Jaggy road one mile south of Manor and ten miles northeast of Vancouver. Telephone, Vancouver 6-F-22. 